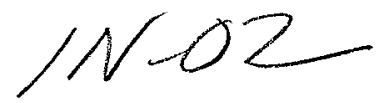

NASA Technical Memorandum 107423

027461

AIAA-97-0174

\title{
Modern Airfoil Ice Accretions
}

Harold E. Addy, Jr., Mark G. Potapczuk, and David W. Sheldon

Lewis Research Center

Cleveland, Ohio

Prepared for the

35th Aerospace Sciences Meeting \& Exhibit

sponsored by the American Institute of Aeronautics and Astronautics

Reno, Nevada, January 6-10, 1997

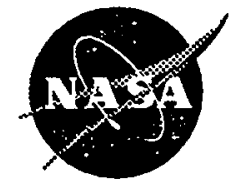

National Aeronautics and

Space Administration 
| 


\title{
Modern Airfoil Ice Accretions
}

\author{
by \\ Harold E. Addy, Jr.*, Mark G. Potapczuk*, and David W. Sheldon \\ NASA Lewis Research Center, Cleveland, Ohio
}

\begin{abstract}
$\underline{\text { Abstract }}$
This report presents results from the first icing tests performed in the Modern Airfoils program. Two airfoils have been subjected to icing tests in the NASA Lewis Icing Research Tunnel (IRT). Both airfoils were two dimensional airfoils; one was representative of a commercial transport airfoil while the other was representative of a business jet airfoil. The icing test conditions were selected from the FAR Appendix $\mathrm{C}$ envelopes. Effects on aerodynamic performance are presented including the effects of varying amounts of glaze ice as well as the effects of approximately the same amounts of glaze, mixed, and rime ice. Actual ice shapes obtained in these tests are also presented for these cases. In addition, comparisons are shown between ice shapes from the tests and ice shapes predicted by the computer code, LEWICE for similar conditions. Significant results from the tests are that relatively small amounts of ice can have nearly as much effect on airfoil lift coefficient as much greater amounts of ice and that glaze ice usually has a more detrimental effect than either rime or mixed ice. LEWICE predictions of ice shapes, in general, compared reasonably well with ice shapes obtained in the IRT, although differences in details of the ice shapes were observed.
\end{abstract}

\section{Nomenclature}

$\mathrm{CL}=$ lift coefficient

$\mathrm{cd}=$ section drag coefficient

$\mathrm{c}=$ airfoil chord length, in.

LWC = liquid water content, $\mathrm{g} / \mathrm{m}^{3}$

MVD = median volumetric diameter, microns

$\mathrm{Tt}=$ total air temperature, ${ }^{\circ} \mathrm{F}$

$\mathrm{V}=$ airspeed, $\mathrm{kts}$.

$\mathrm{x}=$ distance parallel to surface, in.

$y=$ distance normal to surface, in.

Copyright $(1997$ by the American Institute of Aeronautics and Astronautics, Inc. No copyright is asserted in the United States under Title 17, U.S. Code. The U.S. Government has a royalty-free license to exercise all rights under the copyright claimed herein for Governmental Purposes. All other rights are reserved by the copyright owner.

*Aerospace Engineer, Icing Branch, NASA Lewis Research Center. Member AIAA.
Introduction

Since the early 1950 's, a number of airfoils and wing sections have been subjected to controlled aircraft icing conditions in icing wind tunnels. The resulting ice accretions were documented primarily in terms of ice shape and impingement limits for various icing conditions. Most of the documentation from these studies is limited to ice accretions on basic airfoil and wing geometries, such as the two dimensional, NACA 0012 airfoil. In some instances, aerodynamic performance changes due to the presence of an ice accretion on the airfoils were measured. However, most of these measurements were made in dry wind tunnels using prefabricated, two dimensional, artificial ice shapes.

The aviation industry, including aircraft and ice protection system manufacturers, as well as NASA and the FAA, have expressed a need to expand the database of ice accretions to include data for airfoils and wings which are more typical of those in use on today's aircraft. In addition to more advanced two dimensional airfoils, three dimensional airfoils and wings were to be included in the investigation. Moreover, the aerodynamic effects of more realistic, three dimensional ice shapes on these airfoils and wing sections were to be part of the study as well. This database would be useful for not only airfoil design, but also for numerical icing simulation code development.

In response to these needs, the Icing Branch at NASA's Lewis Research Center initiated the Modern Airfoils program. The primary objectives of this program are: 1) document ice shapes from airfoils typical of those in use today, 2) document the aerodynamic effects of these ice shapes, and 3 ) use the ice shapes to verify numerical icing simulation codes. The results of this effort will yield a database of ice shapes formed on modern airfoils which can be used for both time-honored design techniques as well as for computational ice accretion modeling techniques.

\section{Approach}

The airfoils selected for the Modern Airfoils program were to be representative of four different categories of 


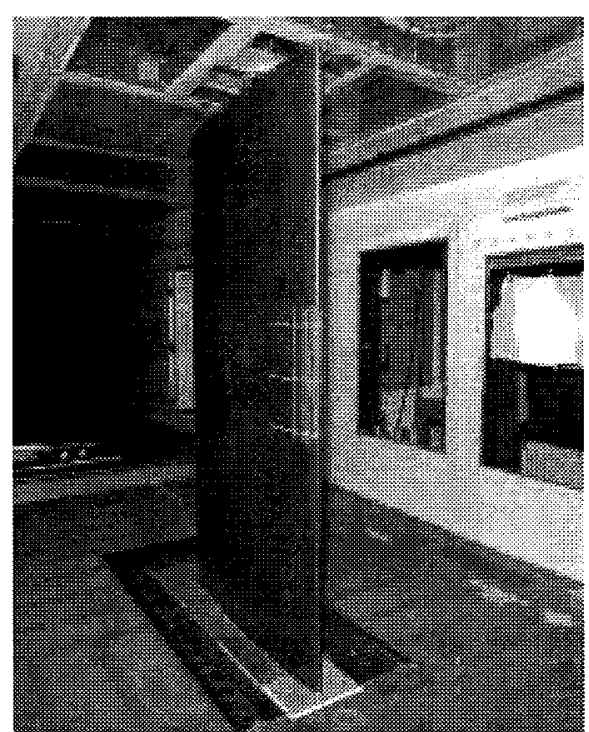

Fig. 1 Commercial Transport airfoil

aircraft: commercial transports, business jets, rotorcraft, and general aviation aircraft. Airframers from throughout the country were asked to provide airfoil geometries to the Icing Branch at NASA Lewis which would demonstrate icing characteristics more applicable to aircraft in design, production, and service today. From the geometries provided, NASA chose representative airfoils for the commercial transport and for the business jet categories of aircraft. Results of the tests involving these two airfoils are described herein. Tests of airfoils representative of the other categories as well as three

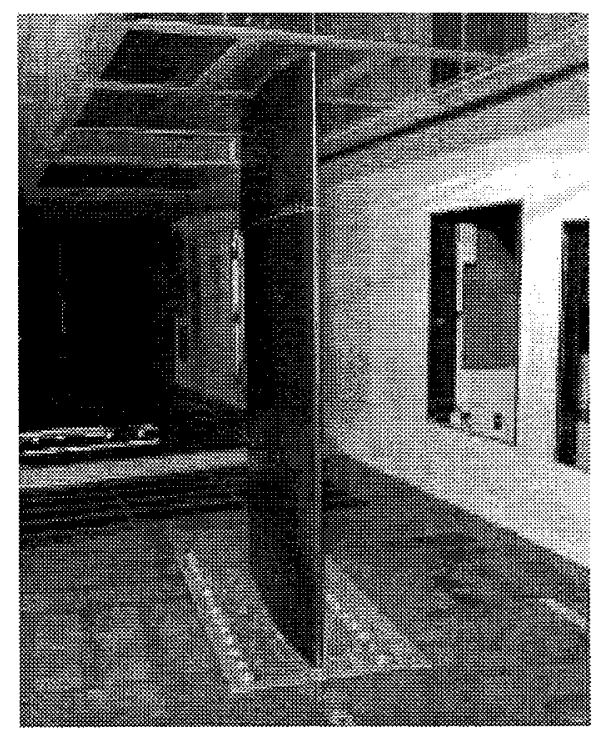

Fig. 2 Business Jet Airfoil dimensional airfoils are being planned and will be included in follow-on reports.

The airfoils described in this report were two dimensional, single-element airfoils. Photographs of the two airfoils are shown in Figs. 1 and 2. Figure 3 shows a cross section of each airfoil. The commercial transport airfoil approximates an airfoil section found on the horizontal tailplane of a large commercial transport aircraft. The business jet airfoil approximates an airfoil section found on the main wing of a business jet aircraft. Twodimensional airfoils reduce the complexities associated with aerodynamic testing so that a basic understanding of their characteristics can be gained. Furthermore, these airfoils produced results more directly simulated by two-dimensional ice accretion codes such as LEWICE. As previously stated, verification of ice accretion computer codes is a major component of the modern airfoils program.

The icing conditions selected for these tests were from the FAR Appendix $\mathrm{C}$ envelope. The airfoils were subjected to icing conditions for time periods designated as short ( 2 minutes), medium (6 minutes), and long (22.5 minutes). Air velocities and airfoil attitudes for the tests

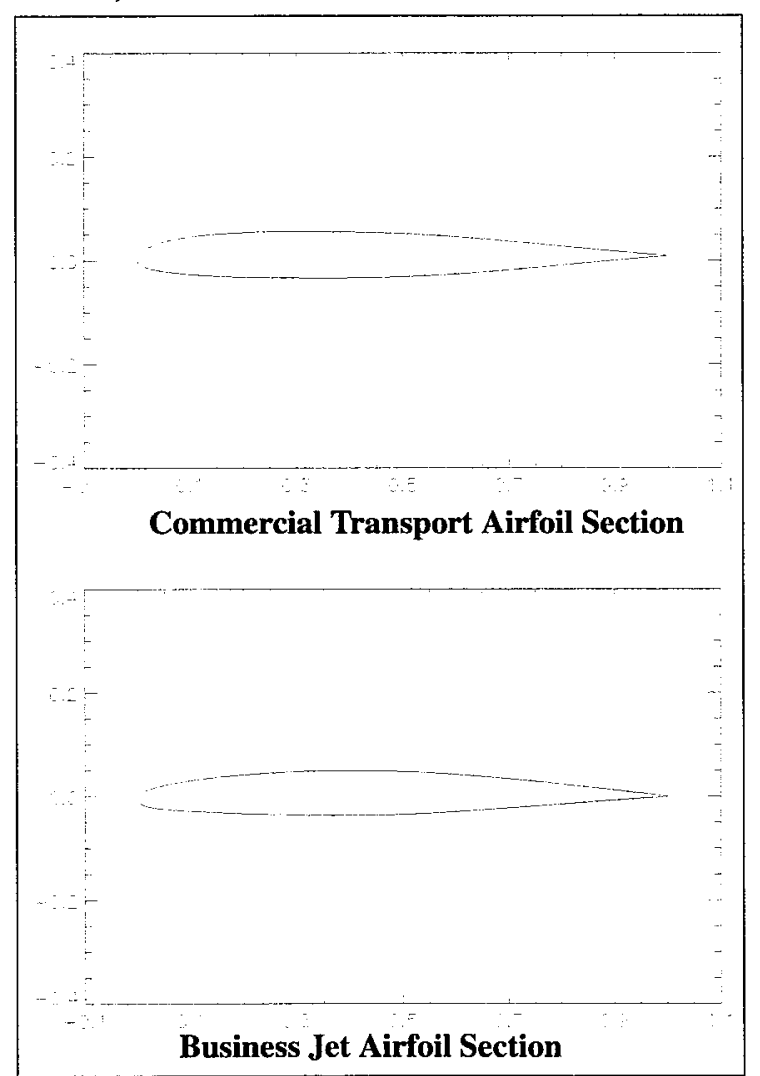

Fig. 3. Airfoil Cross Sections 
were selected to be representative for those each type of airfoil would typically experience in actual service. Thus, the test velocities and airfoil attitudes were different for the two airfoils. Airfoil attitude is the angle of the chord of the airfoil with respect to the tunnel centerline. Airfoil angle of attack is the angle of the chord of the airfoil with respect to the airflow. In this discussion, where standard wind tunnel correction factors, as recommended by Pope ${ }^{1}$, have been applied to correct for wind tunnel wall effects, the term "angle of attack" is used. There may be a small degree of flow angularity present in the IRT which has not been accounted for in the angle of attack data discussed here, however. While this fact should not have a large effect on the data presented here, it should be kept in mind when interpreting these data.

\section{Airfoil Description}

The airfoils were two-dimensional airfoils designed and fabricated specifically for vertical installation in the IRT. Each airfoil has a nominal span of seventy-two inches and a chord of thirty-six inches. A total of forty-four surface static pressure orifices were available for each airfoil. The static pressures were aligned in the chordwise direction with two thirds of the pressure taps forward of the fifty percent chord. These taps were thirty inches above the tunnel floor. In addition, six thermocouples (Type K) were installed. Five of these thermocouples were aligned in the chordwise direction around the leading edge at a height of thirty-nine inches off the floor. The sixth thermocouple was at the leading edge and twenty seven inches from the tunnel floor.

The same construction technique was used for both airfoils and was as follows: first, two metal templates of the airfoil section were made to be used as cutting guides for a male pattern. The templates were then mounted and aligned on each end of a block of laminated bass wood. The wooden block was then machined in the spanwise direction to produce a male pattern of the two-dimensional airfoil. This pattern was used to fabricate a female fiberglass mold. The mold was made in two separate halves which intersected at the zero reference line of the airfoil. The next step was the actual lay-up of the airfoil section. The skins were laid up to a 3/8" thickness using West System Epoxy and fiberglass matting. After the skins dried, the ends were trimmed and the leading and trailing edges were machined flat to the zero reference line (split line). The next step was to add two, 2" thick wooden spars and seven, 1" thick wooden ribs. The spars and ribs were also surface cut along the split line. The top and bottom ribs were located $1 / 2$ " from the end so that a $1 / 2$ " aluminum mounting plate could be installed. The ribs and spars were then epoxied to the skins using a filler of coloidical silica to help fill in any voids. The two halves were clamped together until the epoxy hardened. After the epoxy cured, the two halves were split apart to install the pressure taps and thermocouples.

The static pressure taps were made with 0.040 " OD stainless steel tubing. The tubing was routed out through the ceiling mount. Each thermocouple was embedded in the fiberglass skin. A hole was counterbored from the inner surface to a depth of 5/16". Then the thermocouple was installed in the counterbore and back filled with epoxy. The thermocouple leads were routed through the ceiling mount similar to the pressure tubing. After the instrumentation was installed, the two halves were epoxied together with a mixture of coloidical silica filler and epoxy.

The first rib on each end was recessed $1 / 2$ " so that an aluminum plate could be installed at each end of the airfoil using the epoxy silica mixture. Holes were then drilled and tapped through the outer surface into the aluminum plates so that the airfoil could be mounted in the test section of the IRT.

The airfoils were mounted vertically in the IRT test section. The suction surface for the commercial transport tail airfoil faced the main control room while the suction surface for the business jet wing airfoil faced the secondary control room. Pitch was controlled with the facility test section turntable. An external force balance system was attached and integrated into the turntable and ceiling structure.

Each airfoil was secured in the tunnel test section using bolts which passed through the balance flanges and into the aluminum end plates. The external force balance measured loads acting in the horizontal plane. This was accomplished using two reaction points. One reaction point resided in the turntable at the floor of the tunnel; the other resided in the ceiling of the test section. Loads transmitted to the floor and ceiling attachments were measured and recorded independently.

The force balance system was designed to move with the turntable and airfoil as they were rotated to change airfoil attitude. It therefore measured forces normal to and parallel to the airfoil chord line regardless of the airfoil attitude.

A wake survey system was used to obtain a measure of airfoil section drag. This system consisted of a movable Pitot probe which traversed the airfoil wake at mid-span 
and at a distance of 1-1/2 chords downstream of the airfoil. Free stream conditions were measured using the facility Pitot-static probe located 2-1/2 chords upstream of the airfoil near the tunnel wall. Total pressures were measured using absolute pressure transducers while static pressures were measured using a differential pressure transducer. The probe position was measured using a distance potentiometer.

Flow visualization was used to observe the onset of flow separation during airfoil rotation and icing. Flow cones from X-Aero System, Inc. in Seattle, WA were employed for this task. A flow cone is a white plastic cone 1-3/4" long and 9/32" in diameter at its base. The cones were attached to the airfoil via a 1-3/4" length of string emanating from the cone's apex. One inch wide aluminum tape was applied over the string near the cone's apex to affix the cone to the airfoil. The extra string was doubled back and taped over with 2 " wide aluminum tape. A row of cones was affixed to each airfoil in a chordwise direction on both the suction and pressure surfaces at a location approximately 18 " from the floor of the tunnel.

\section{Test Description}

Icing conditions for these tests were selected from the FAR Appendix $C$ envelope. They included median volumetric diameter (MVD) water droplet sizes from 15 to 40 microns and liquid water contents (LWC's) from 0.3 to 0.6 grams per cubic meter. For certain points in the envelope, the IRT's icing cloud conditions were scaled to simulate LWC's as low as $0.1 \mathrm{~g} / \mathrm{m}^{3}$.

Air temperatures were also based upon the Appendix C data and corresponded to the selected icing cloud conditions. These static air temperatures ranged from $-20^{\circ} \mathrm{C}$ to $-5^{\circ} \mathrm{C}$. Corresponding total temperatures ranged from $12^{\circ} \mathrm{C}$ to $0^{\circ} \mathrm{C}$.

The airspeeds and attitudes were chosen to reflect those that each type aircraft would experience during an icing encounter and, in particular, during a hold condition. These airfoil attitudes ranged from $0^{\circ}$ to $6^{\circ}$ and the Mach numbers ranged from 0.28 to 0.40 . The desired Mach number for the commercial transport was 0.45 , however, this airspeed was higher than the IRT could achieve due to airfoil blockage. Therefore, these tests were run at a Mach number of 0.40 and the icing conditions were scaled using the Olsen method ${ }^{2}$ to achieve an ice shape representative of the Mach 0.45 condition.

A typical test run consisted of several steps. First the airfoil was set at the given attitude. Then the tunnel air and airfoil were brought to the desired temperature at the proper airspeed. A wake survey was then conducted to measure the clean airfoil drag. Force balance measurements were also taken for the clean airfoil. The airfoil was then subjected to the predetermined icing conditions for the specified amount of time. Force balance measurements were usually taken during the icing event. After the icing cloud was terminated, another wake survey was taken and final force balance measurements were recorded. The tunnel fan was then brought to a stop such that detailed records of the ice shape could be made and force balance zeros could be recorded. Photographs of the accreted ice were taken with a $35 \mathrm{~mm}$ camera. Then the ice was cut, using a warm aluminum template, in three spanwise locations: 18 ", 36 ", and 54" from the floor, so that hand tracings using a pencil and cardboard template could be made of the ice shape profile. The ice thickness was measured at each of these cuts using a depth gage. Typically, three ice depth measurements were made at each cut: a suction surface maximum ice thickness, a stagnation line ice thickness, and a pressure surface maximum ice thickness. The ice was then cleaned off the airfoil and the tunnel cleared for the next test run.

For selected test runs, after ice had accreted, the airfoil was rotated through a range of attitudes while measuring the lift forces with the force balance system. These data could then be used to help determine the effect of the ice on aerodynamic stall. A line of flow cones attached to the airfoil in a chordwise direction were used to visually observe the onset of stall as the airfoils were rotated. This method involved a degree of subjective judgment which lead to a rather high degree of variability in estimation of the angle of stall. It was found that airfoil rotation past the point of visually observed stall resulted in excessive airfoil vibration. Therefore, airfoil rotation was stopped at a point just prior to excessive airfoil vibration, precluding the measurement of poststall aerodynamic forces.

Finally, molds were made of a few select ice shapes. The number of ice shape molds made was limited because it took several hours for the mold material to set after it had been poured in place on the airfoil in the tunnel. Therefore, a mold could only be made for the last test run of the shift. These molds provide a reasonably accurate record of the surface roughness of the ice and they can to be used to make artificial reproductions of the ice. These artificial ice shapes can be installed on the airfoils and tested for aerodynamic performance in an aerodynamic wind tunnel to substantiate the measurements made in the IRT. 
$\underline{\text { Results }}$

In this report, significant results from the icing tests of the two airfoils will be discussed. First, the repeatability and accuracy of the experimental results will be discussed to bound the domain of the evaluation. Then, several IRT ice shapes formed under the same icing conditions at various icing time intervals will be discussed along with their corresponding effect on aerodynamic performance. Next, the effects of differing ice conditions at the same icing time interval are presented. Finally, several comparisons of LEWICE results with IRT ice shapes will be presented.

\section{Experimental Repeatability and Accuracy}

In order to determine the variability of the ice shapes and resulting force measurements for a given icing condition, several tests were repeated during each airfoil's test period in the IRT. The external force balance system was used to measure lift forces while the wake survey system was used to measure drag forces. Figure 4 shows

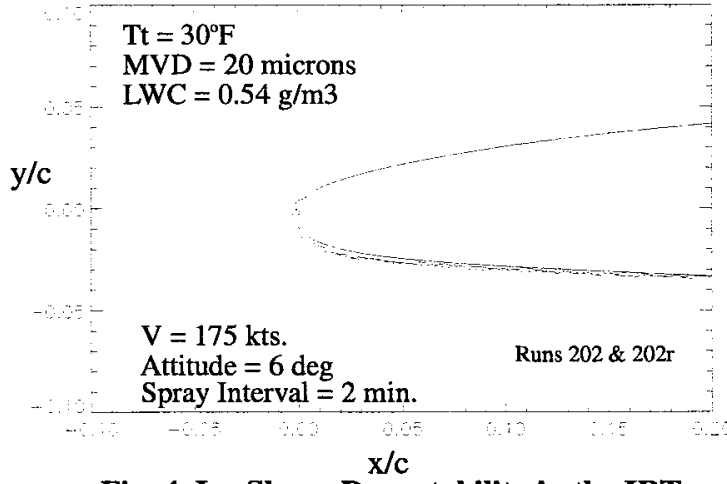

Fig. 4. Ice Shape Repeatability in the IRT

two ice tracings taken at the airfoil centerline on the business jet airfoil for two separate test runs at the same icing conditions. The amount of variation in ice shape indicated in this figure is typical for the IRT, as has been shown in previous studies ${ }^{3}$. Figure 5 shows lift versus angle of attack curves for these same two test runs as well as a third curve which was from a third run at the same test conditions. A mold was made of the ice on this third test run which precluded cutting the ice at the airfoil centerline to obtain a tracing. This figure shows the variation in estimation of stall angle brought about by the rather subjective technique used to establish this parameter, as was noted earlier. For these three test runs, the visually estimated angle of stall ranged from 11.3 to 12.7 degrees; a variation of $12 \%$. However, very little variation in the highest measured lift coefficient was found for these three cases. The highest lift coefficients

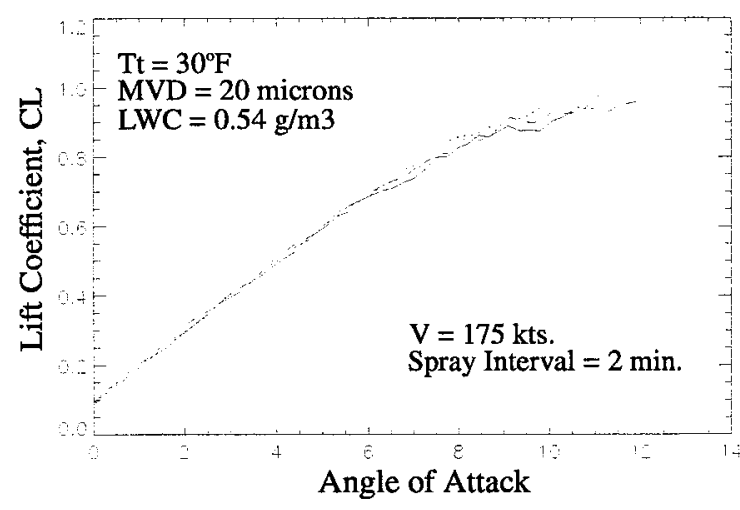

Fig. 5. Repeatability of Lift Curves in IRT

for these runs ranged from 0.885 to 0.904 ; a variation of $2 \%$. Thus, the repeatability of the highest measured lift coefficients was good for these tests, while the estimated stall angle was somewhat less repeatable, primarily due to the method of measurement.

Good repeatability of the force measurements was also found in the data recorded at the attitude at which ice was accreted on the airfoil. This repeatability is demonstrated in the bar charts of Figs. $6 a$ and $b$. Figure $6 a$

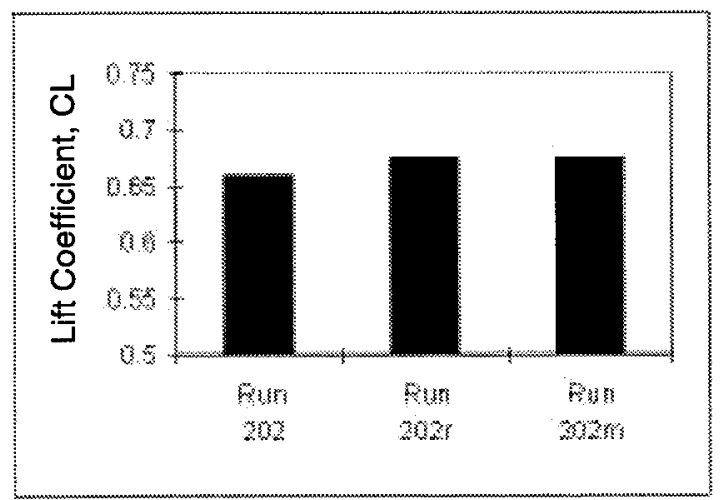

Fig. 6a. Repeatability of Lift Coef. for Separate Tests Run at Same Conditions

shows the lift coefficients for the same three test runs described above. These lift coefficients were measured using the force balance after ice had been accreted. The airfoil was held at the attitude of six degrees where the ice had been accreted. Again, the lift coefficient varied by about $2 \%$ over the three runs. The section drag coefficients as measured by the wake survey system also showed good repeatability, varying by less than $1 \%$ as indicated in Fig. $6 \mathrm{~b}$. 


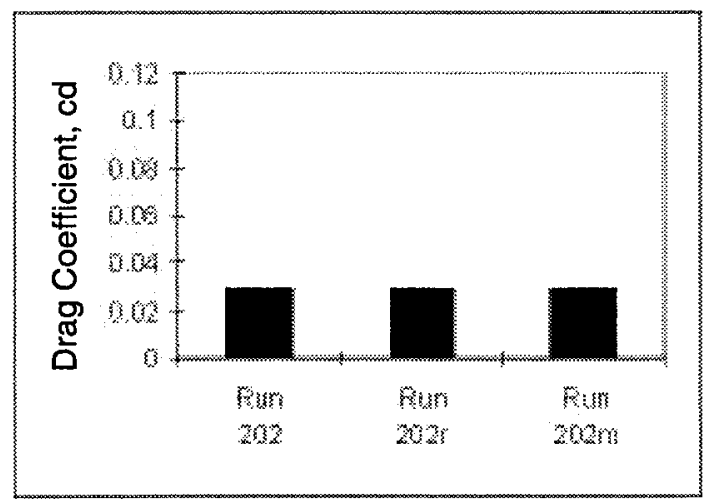

Fig. 6b. Repeatability of Drag Coefficient for a Given Icing Condition

Standard wind tunnel correction factors as recommended by Pope $^{1}$ have been applied to the data presented in this report. Force measurements made during these tests were accurate to within $\pm 5 \%$. However, the force measurements made with ice accreted on the airfoils need to be interpreted cautiously. Wind tunnel airflow is affected by the size of the airfoil's wake. Ice accretions can have a tremendous effect on the size of the airfoil's wake; increasing its breadth by as much as four to five times or more depending upon the amount and type of ice. Whether standard wind tunnel corrections can adequately account for this is questionable. Furthermore, the icing cloud was not uniform over the entire span of the airfoil. In fact, while ice is normally observed to cover all but about six inches of the span at each end of the airfoil, icing could measurements have shown that the cloud is uniform, in terms of liquid water content, over only about a two to three foot $\operatorname{span}^{4}$ at the center of the airfoil. This fact must be kept in mind

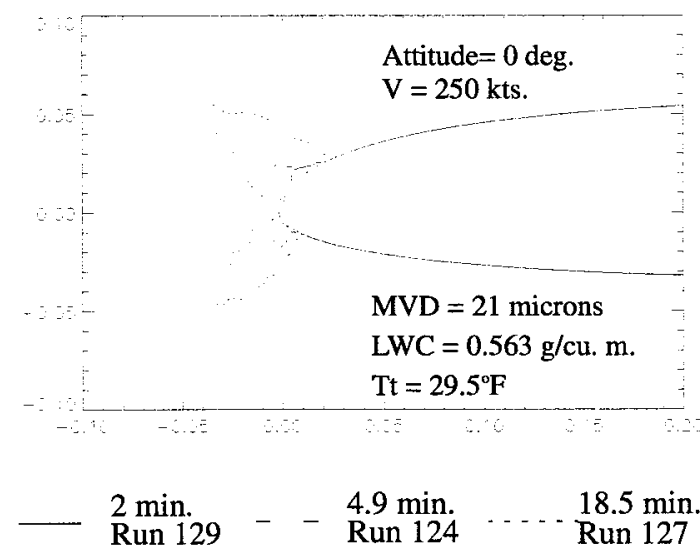

Fig. 7. Glaze Ice Shapes at Varying Cloud Exposure Times on Commercial Transport Airfoil

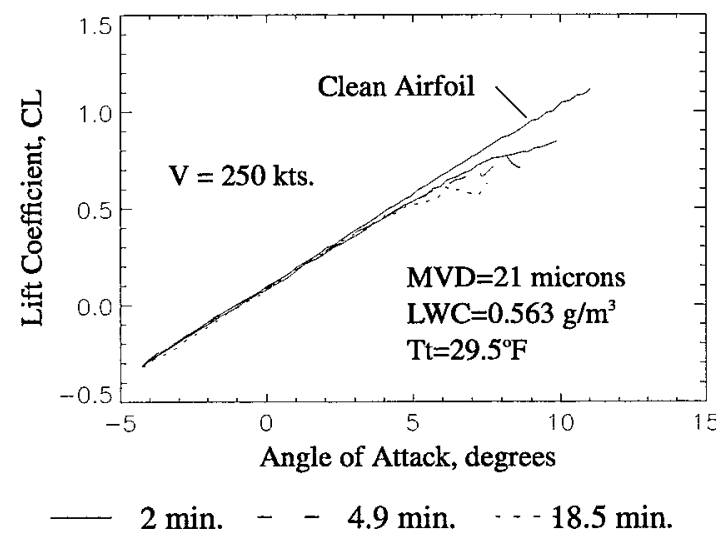

Fig. 8. Effect of Glaze Ice at Varying Exposure Times on Lift Coef. vs. Angle of Attack for Commercial Transport Airfoil

when comparing the clean airfoil measurements to those made with ice on the airfoil.

\section{Experimental Icing Time Interval Tests}

Figure 7 shows three different ice shapes formed at glaze ice conditions on the commercial transport airfoil at an attitude of zero degrees. The ice shapes are for a two minute icing exposure interval, a 4.9 minute icing interval, and an 18.5 minute icing interval. The two longer icing exposure intervals of 4.9 and 18.5 minutes were scaled from the desired icing time intervals of six and 22.5 minutes because the actual Mach No. desired for this airfoil was 0.45 , however, the tests were limited to a Mach No. of 0.40 by tunnel blockage as was discussed earlier. The two minute ice accretion case was not scaled because ice accretions of less than two minutes are often difficult to record owing to the small amount of ice present on the airfoil.

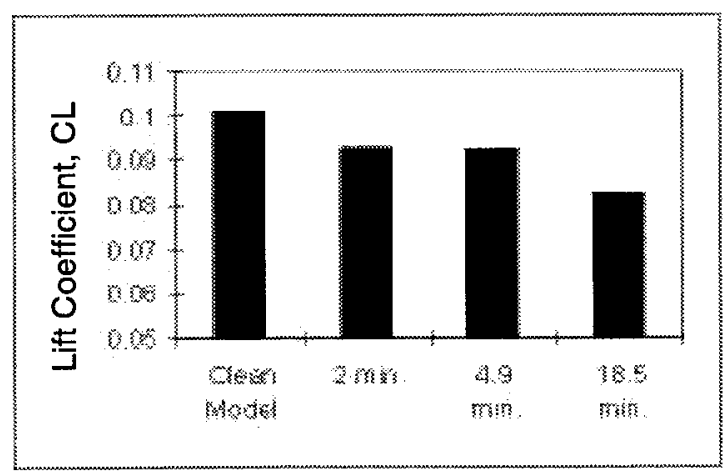

Fig. 9a. Effect of Glaze Ice at Varying Exposure Times on Lift Coef. for Commercial Transport at Ice Accretion Attitude of 0 degrees 


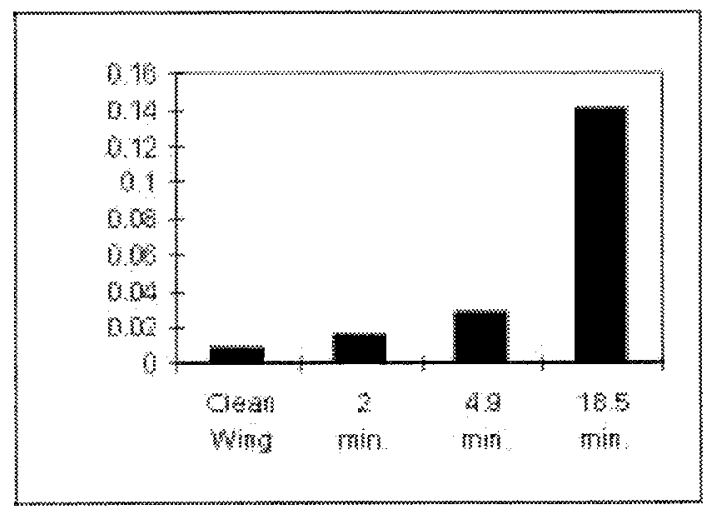

Fig. 9b. Effect of Glaze Ice at Varying Exposure Times on Section Drag Coef. for Commercial Transport Airfoil

Figure 8 shows the effects of these three ice shapes on the observed stall angle and the highest measured lift coefficient for the commercial transport airfoil. As expected, the greatest effect on lift coefficient and stall angle was caused by the largest ice shape. However, a significant decrease in highest measured lift coefficient was also observed for the smallest ice shape. For the two minute glaze ice shape, there was a $24 \%$ decrease in the highest measured lift coefficient. For the 4.9 and 18.5 minute ice shapes, the highest measured lift coefficients decreased by $30 \%$ and $44 \%$, respectively. The observed stall angles decreased from the clean airfoil values by, in the 18.5 minute case, as much as $32 \%$. Figure 9 a shows lift coefficients measured at the ice accretion attitude of zero degrees, for the clean airfoil and each of these same ice shapes. Here, lift coefficient decreased by $9 \%$ for the two minute, $10 \%$ for the 4.9 minute, and $19 \%$ for the 18.5 minute ice shape. Figure $9 \mathrm{~b}$ shows the drag coeffi-

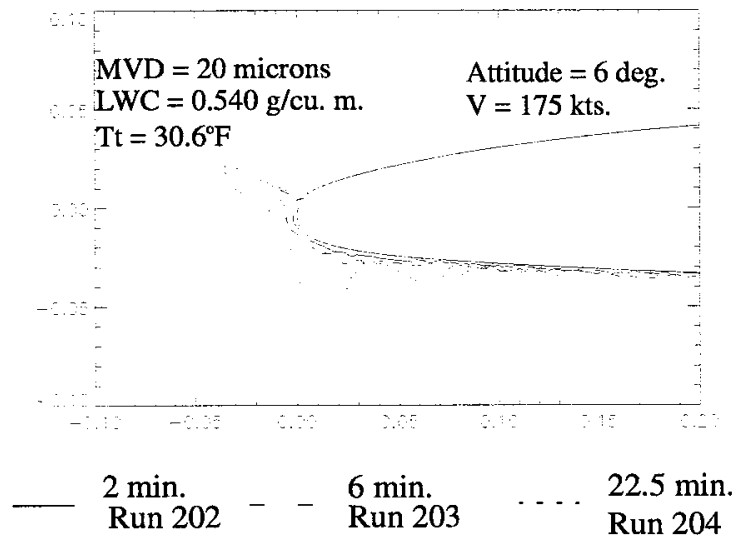

Fig. 10. Glaze Ice Shapes at Varying Cloud Exposure Times on Business Jet Airfoil cients for these same conditions as measured by the wake survey probe.

Glaze ice shapes at various icing time intervals for the business jet airfoil are shown in Fig. 10. These ice shapes were accreted at a airfoil attitude of six degrees. The effects of these ice shapes on highest measured lift coefficient and stall angle are shown in Fig. 11. Again, a small amount of ice results in a significant decrease in highest measured lift coefficient. For the two minute ice accretion, the highest measured lift coefficient decreased by $17 \%$. For the six and 22.5 minute cases, the highest measured lift coefficient decreased by $21 \%$ and $30 \%$, respectively. The largest observed stall angle decrease was $35 \%$ and was caused by the 22.5 minute ice shape. Figure 12 shows bar charts for the lift and drag coefficients measured at the airfoil ice accretion attitude of six degrees. Here, the lift coefficient

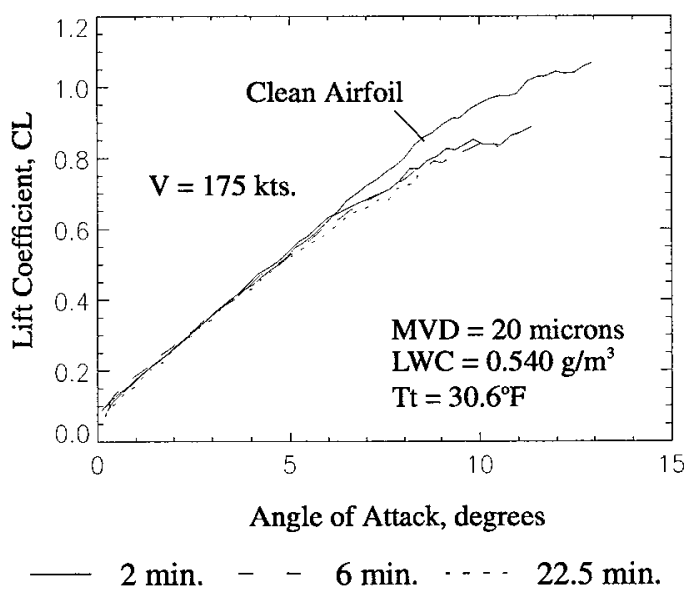

Fig. 11. Effect of Glaze Ice at Varying Exposure Times on Lift Coef. vs. Angle of Attack for Business Jet Airfoil

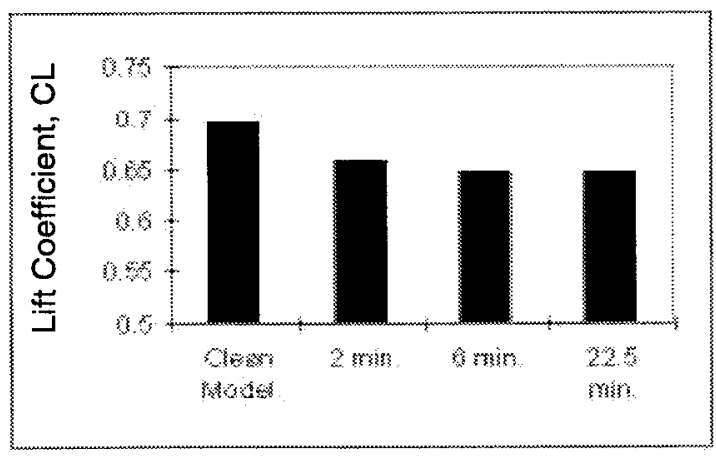

Fig. 12a. Effect of Glaze Ice Shapes at Varying Exposure Times on Drag Coef. for Business Jet Airfoil at the Ice Accretion Attitude 


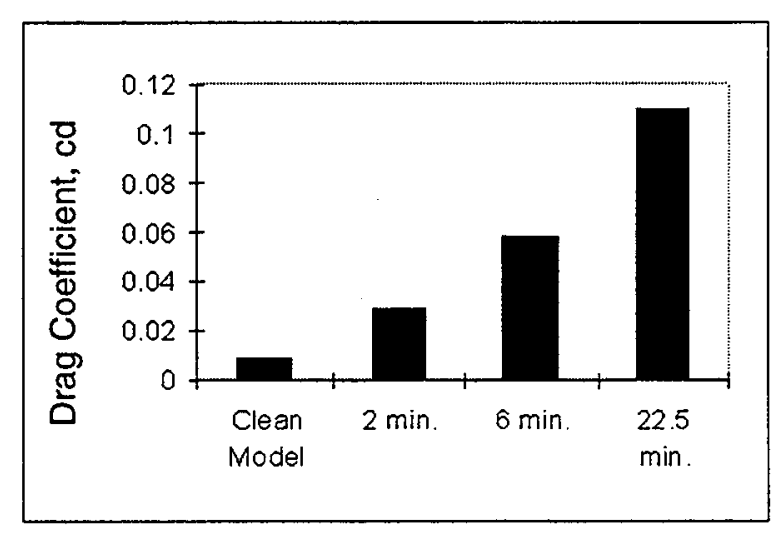

Fig. 12b. Effect of Glaze Ice at Varying Exposure Times on Section Drag Coef. for Business Jet Airfoil

decreased by $5 \%$ for the two minute case and about $7 \%$ for both the six and 22.5 minute cases, as seen in 12a. Corresponding drag values are given in Fig. 12b

Inspection of the bar charts for both airfoils discussed thus far, Figs, 9 and 12, indicates that much of the lift decrement occurs earlier in the icing process then tends to level off while the drag loss tends to continue to increase strongly with time. These trends have been observed in other aircraft icing studies ${ }^{5}$.

\section{Experimental Ice Type Study}

Ice shapes formed on the commercial transport airfoil for differing ice conditions are shown in Fig.-13. Each ice shape was formed during a similar ice accretion time interval, but at a different temperature. The three ice shape accretion temperatures were $29.5^{\circ} \mathrm{F}$,

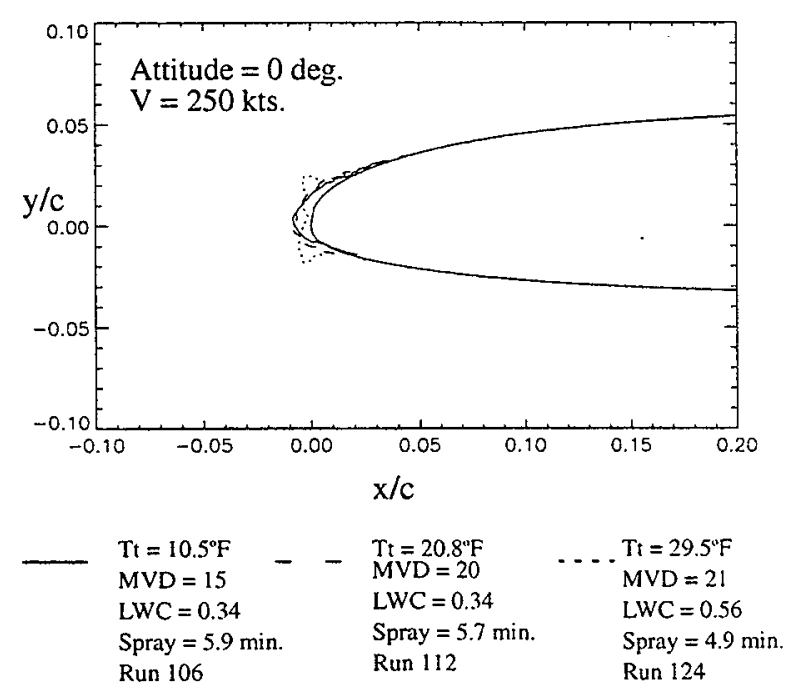

Fig. 13. Various Ice Types on Commercial Transport Airfoil Formed at Similar Icing Exposure Times

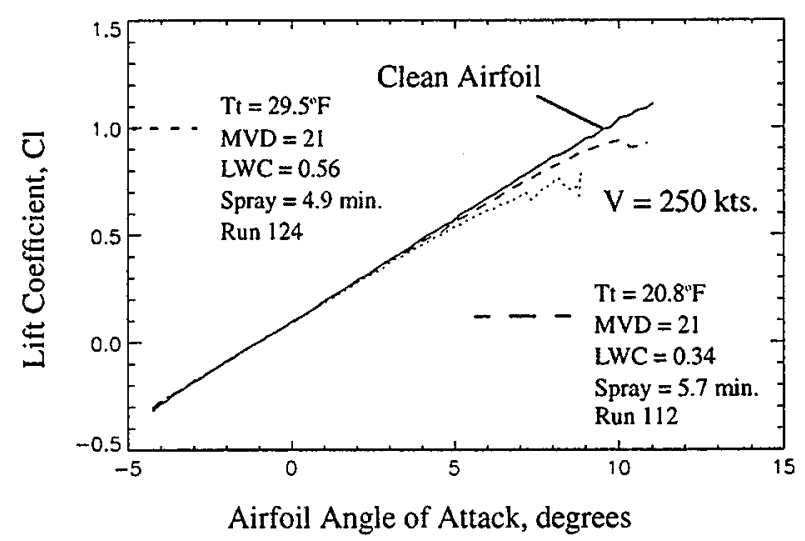

Fig. 14. Effect of Various Ice Types on Lift Coef. for Commercial Transport Airfoil Formed at Similar Icing Exposure Times

$20.8^{\circ} \mathrm{F}$, and $10.5^{\circ} \mathrm{F}$. The $29.5^{\circ} \mathrm{F}$ condition was a glaze ice condition, the $20.8^{\prime \prime} \mathrm{F}$ condition was a mixed ice condition, while the $10.5^{\circ} \mathrm{F}$ condition was a rime ice condition. Again, the ice was accreted at an attitude of zero degrees. The effect of the glaze ice shape and the mixed ice shape on highest measured lift coefficient and observed stall angle are shown in Fig. 14. The mixed ice shape caused a $16 \%$ decrease in the highest measured lift coefficient, while the glaze ice shape resulted in a $30 \%$ decrease in this same parameter. As for observed stall angle, the mixed ice shape showed little noticeable decrease, however, the glaze ice shape caused a decrease of $19 \%$. The airfoil was not rotated to obtain highest measured lift coefficient and stall angle data for the rime ice case.

Lift and drag coefficients for the clean airfoil and for each ice shape at the attitude at which the ice was accreted are shown in Figs. 15a and b.,

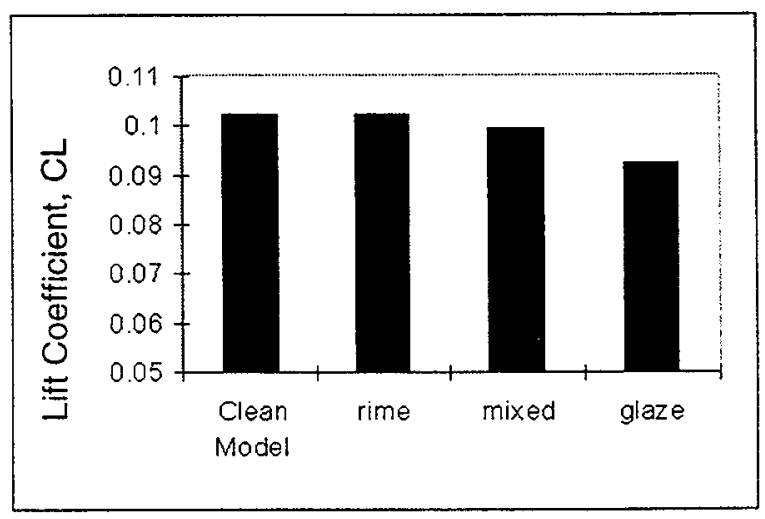

Fig. 15a. Effect of Ice Type on Lift Coef. at Ice Accretion Attitude for Commercial Transport Airfoil 


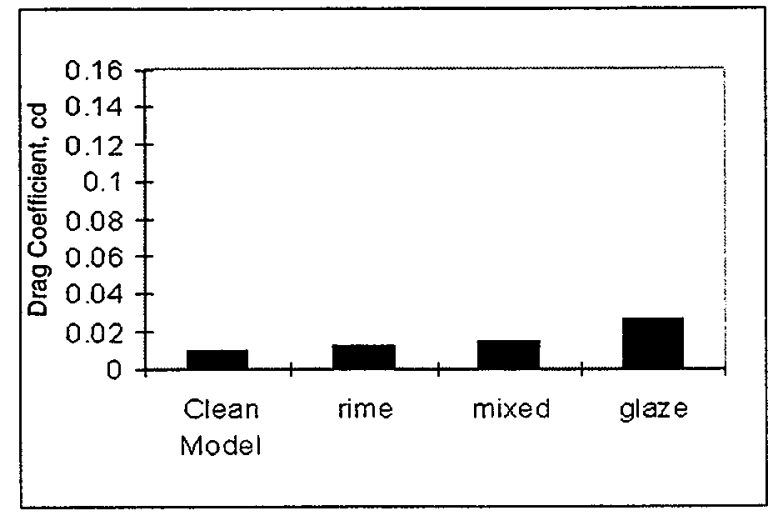

Fig. 15b. Effect of Ice Type on Section Drag Coef. at Ice Accretion Attitude for Commercial Transport Airfoil

The biggest effect on both parameters is caused by the glaze ice shape. It is interesting to note that a slight increase in lift coefficient was caused by the rime ice shape, apparently the airfoil shape was altered slightly such that the lift was increased. It should be noted that this rime ice shape was smooth in comparison to the other ice shapes. This phenomenon has been noted in other studies ${ }^{6}$ and is associated with an effective increase of camber due to the ice shape.

A similar study was performed with the business jet airfoil. The ice shapes from these tests are shown in Fig. 16. The highest measured lift coefficient and stall angle data are shown in Fig. 17. It was interesting to note that the highest measured lift coefficients and stall angles for

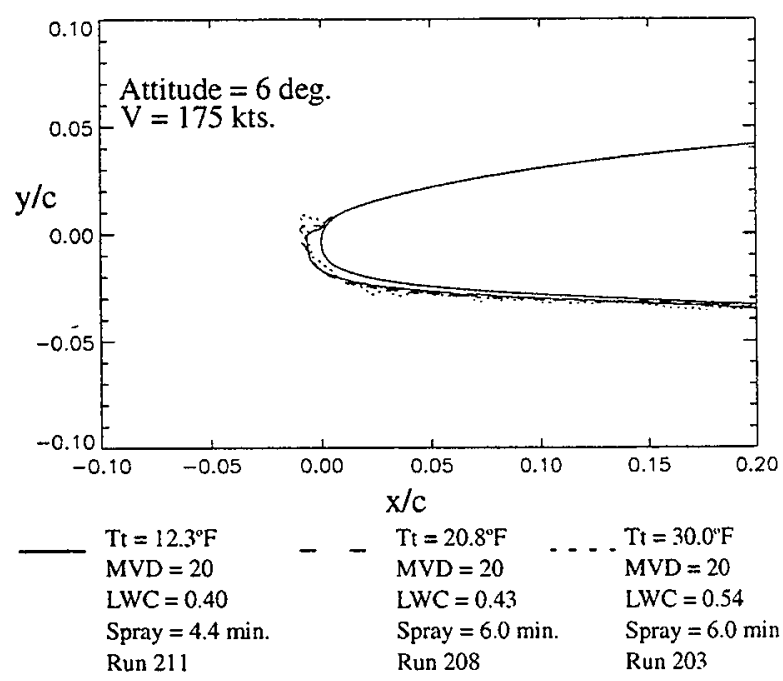

Fig. 16. Various Ice Shapes on Business Jet Airfoil at Similar Icing Exposure Times

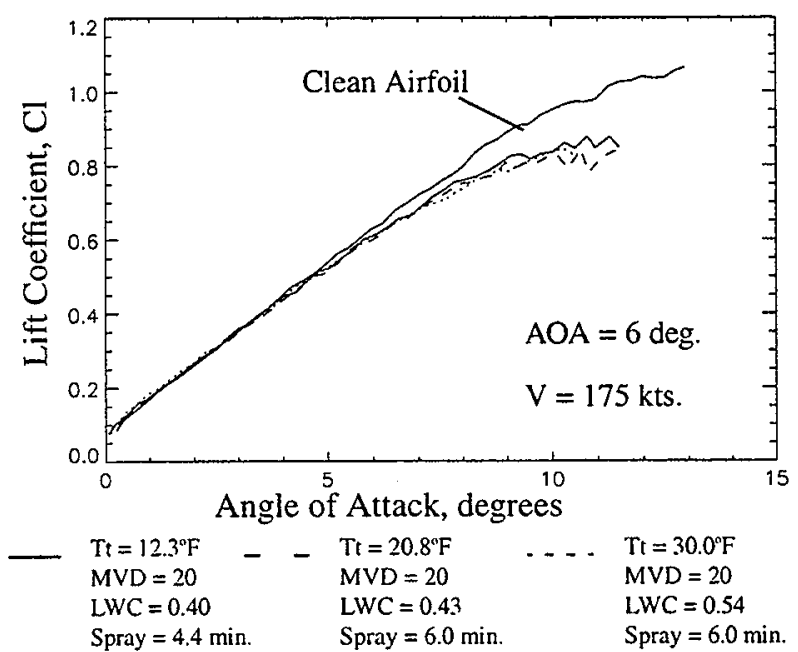

Fig. 17. Effect of Various Ice Shapes on Lift Coef. vs. Angle of Attack for Business Jet Airfoil at Similar Icing Exposure Times

the rime and mixed ice cases were the same, although the lift curves varied slightly. Interestingly, the decrease in highest measured lift coefficient for each of these cases was $21 \%$. The decrease in observed stall angle was $11 \%$ for both the rime and mixed ice shapes and was $19 \%$ for the glaze ice shape. It should be noted that these ice shapes are more similar than those for the commercial transport airfoil.

The lift and drag coefficients from each of these ice shapes as well as the clean business jet airfoil measured at the ice accretion attitude are shown in the bar charts in Figs. 18a and $b$. The glaze ice shape causes about the same lift loss as the rime and mixed ice shapes, but a greater increase in drag.

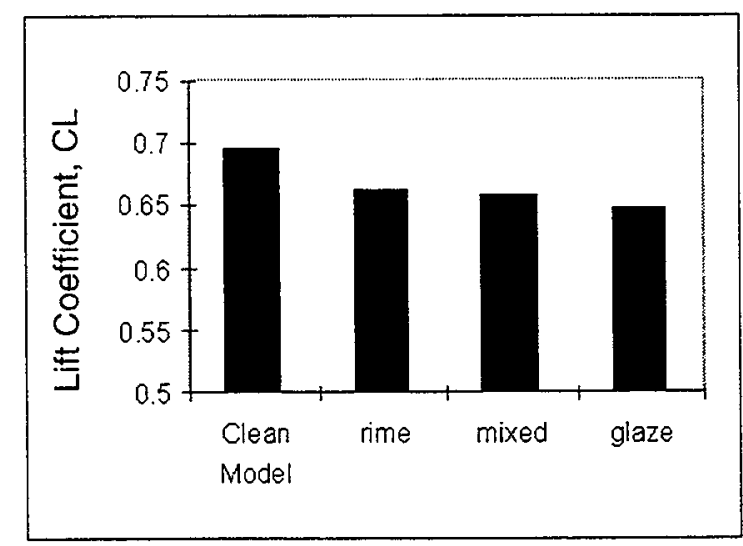

Fig. 18a. Effect of Various Ice Types on Lift Coef. at the Ice Accretion Attitude for the Business Jet Airfoil 


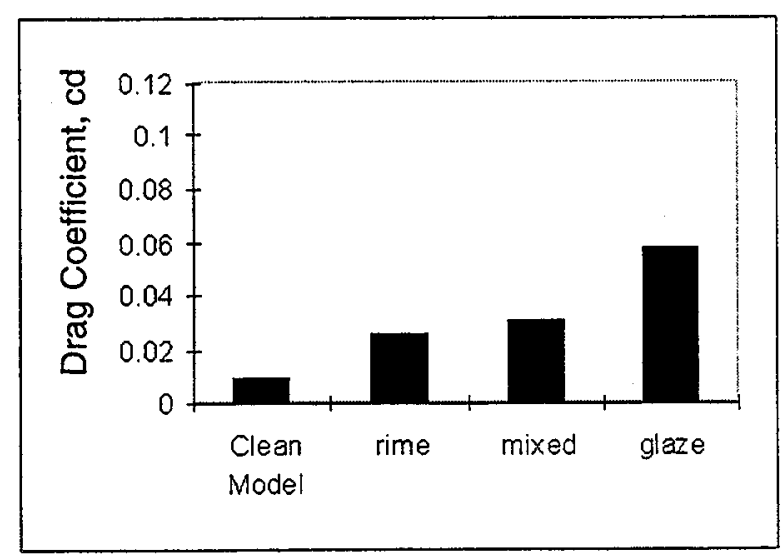

Fig. 18b. Effect of Various Ice Types on Section Drag Coef. at the Accretion Attitude for the Busi-

\section{LEWICE Calculations of Ice Shapes}

One of the primary reasons for performing these tests is use of the data for validation of computer codes, such as the NASA Lewis ice accretion prediction code LEWICE. As such, it was decided to perform some initial evaluations of LEWICE by comparing code results to the digitized tracings of the ice shapes presented previously. The code was run in the version 1.6 configuration without modification. The input data consisted of the clean airfoil geometry, the IRT tunnel conditions, and input flags set to allow automatic selection of roughness size, time step, control volume size, and turning angle between control volumes. These parameters and other features of the LEWICE code are described in the most recent update to the User's manual ${ }^{7}$. No attempt was made to adjust or optimize the LEWICE calculations to improve the comparisons. This exercise was undertaken to determine how well the code compares in its current version and to evaluate what improvements to the modeling may be required for future versions.

\section{Business Jet Airfoil Comparisons}

The first set of comparisons are for an airfoil representative of a business jet main wing section. The results are shown in Figures 19-21. Figure 19 shows two LEWICE calculations compared to the ice shape tracing from Run \#206. This test is a 4.2 minute rime ice accretion with the test conditions as shown in the figure.

The LEWICE calculations were performed at two different angle of attack conditions in order to determine if varying this parameter could result in better agreement with test results. From the code results, it is apparent that changing the angle of attack from the airfoil attitude in the IRT of six degrees to five degrees resulted in a somewhat better agreement between test and computa-

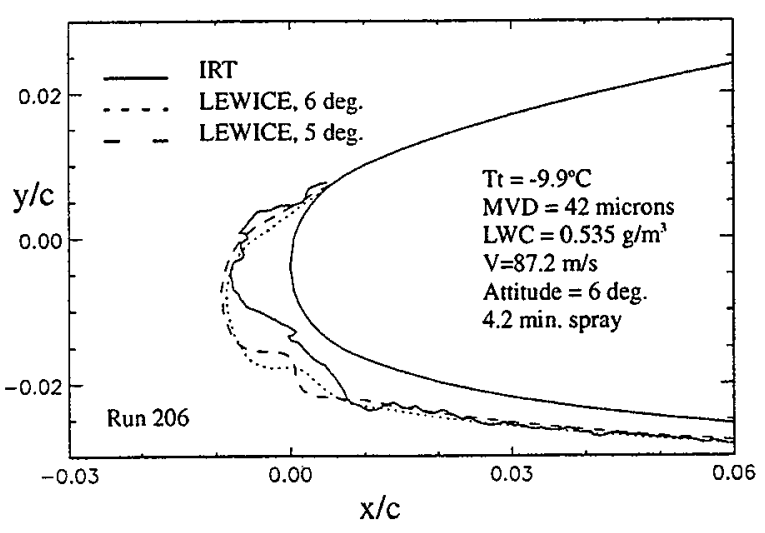

Fig. 19. IRT Ice Shape Compared with LEWICE Predictions

tion. This, of course, could be due to either errors in the code or to variations in the aerodynamic flow angle in the tunnel. This suggests that pressure measurements of the airfoil should be taken prior to testing in the IRT and that matching of lift results should be done for code/tunnel comparisons.

The next LEWICE calculation, shown in Fig. 20, does not agree with the measured ice shape as well as the previous case. The impingement limits and the orientation of the main ice accretion seem to have been predicted

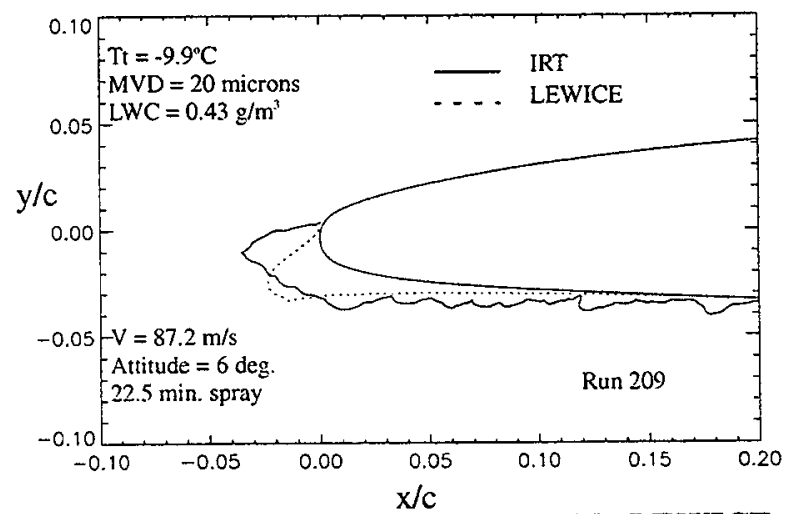

Fig. 20. IRT ice shape compared with LEWICE prediction for Business Jet Airfoil.

well, but the total ice mass is under-predicted by the code. The LEWICE calculation shows a single horn shaped structure apparently growing into the flow direction, results indicative of a rime ice structure. The experimental results indicate a flattened surface roughly perpendicular to the incoming flow stream. This type of formation is characteristic of a mixed rime-glaze ice accretion. These two facts, lower ice mass and rime accretion instead of mixed, suggest a possible mecha- 
nism for the discrepancy. If the total water catch is lower than occurred in the experimental results, then the heat transfer rate could be high enough to result in freezing on impact instead of the water runback situation found in mixed ice accretions. The results suggest further evaluation of the flowfield results from the potential flow calculation in LEWICE.

The last business jet airfoil section test case examined was for a 16.7 minute ice accretion. The temperature condition for this test was somewhat lower than the previous two cases and the measured ice shape exhibited more rime like features. As a result, the agreement between computation and experiment was somewhat better than for the previous case. Figure 21 shows the comparison and the ice accretion limits, ice mass, and general shape all indicate reasonable agreement. The experimental shape still has a broader central structure than that of the LEWICE calculation, however the central peak of the experimental shape is starting to take on the more pointed structure that is indicative of the LEWICE calculation. Again, the ice mass is under-predicted by the LEWICE code and a situation similar to the previous case is the result.

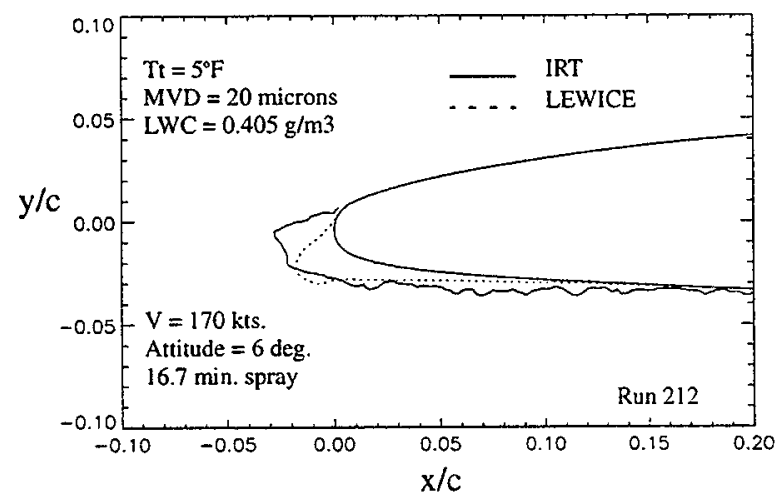

Fig. 21. IRT Ice Shape Compared with LEWICE Predictions for Business Jet Airfoil

In all three of these comparisons the LEWICE results showed considerable extents of ice along the lower surface. This trend was also observed in the experimental results. However, the LEWICE calculations do not produce the degree of roughness in this region that is exhibited by the ice shape tracings. This is typical of LEWICE results in general and suggests that further examination is required to determine what physical process results in these roughness elements. Such efforts are currently underway at the NASA Lewis Research Center, however a computational model of the development of these roughness elements has not been completed.
Commercial Transport Airfoil Section Comparisons

The other set of comparisons performed for this study were for an airfoil representing a section cut from a typ-

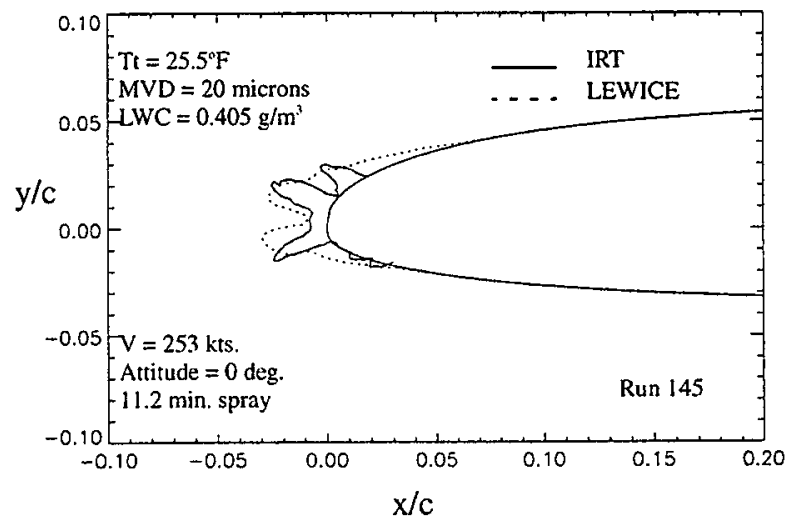

Fig. 22. IRT Ice Shape Comparison with LEWICE Prediction for Commercial Transport Airfoil Section

ical commercial transport horizontal tail. These results are shown in Figures 22 through 25. In general, the ice shapes calculated by LEWICE for this airfoil capture the features of the experimental results better than the previous set of calculations. This may be due to the fact that this airfoil is thicker than the business jet airfoil and closer to the type of geometry that LEWICE was developed to model. Further examination of the details differentiating these airfoil geometries, such as pressure distribution, boundary layer development, and convective heat transfer distribution will be required to understand how the ice accretion is affected and how the computational modeling must be modified.

The comparison between LEWICE and experimental results, shown in Figure 22, is quite good. The code captures the shape, orientation, mass, and icing limits found in the IRT results. The results agree to within the repeatability of the experimental measurements.

The next comparison is for Run $\# 123$, an 18.5 minute accretion exhibiting substantial glaze horn growth. In this case, the LEWICE calculation captures the dramatic double horn ice shape characteristic of glaze ice accretions and the general orientation and size of the ice mass, as shown in Figure 23. The code does not successfully predict the horn angle found in the IRT results. The horns from the IRT produced shape grow out in a direction essentially normal to the local surface. In contrast, examination of the ice growth layers, shown in Figure 24 , indicate that the LEWICE results exhibit initial 


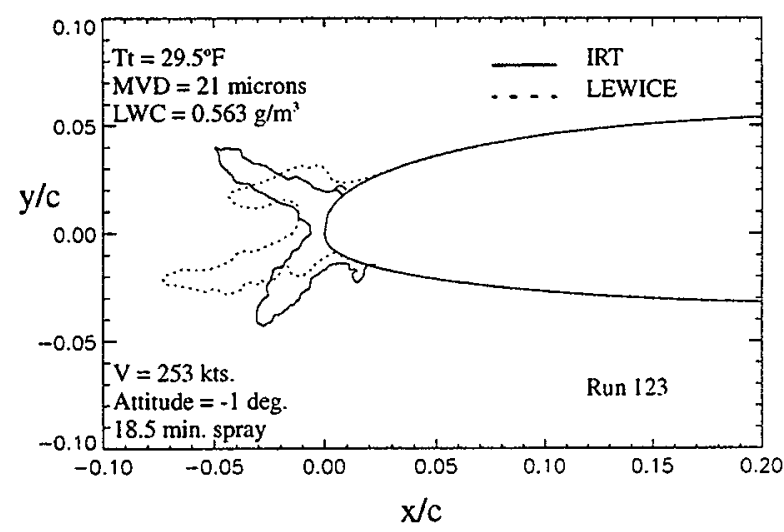

Fig. 23. IRT Ice Shape Comparison with LEWICE Prediction for Commercial Transport Airfoil Sec-

growth normal to the surface followed by growth into the flow direction at later stages of the process.

In the LEWICE ice growth model, local freezing fraction values less than one result in growth normal to the surface while a freezing fraction of one results in growth parallel to the local droplet trajectory (i.e. essentially parallel to the local flow direction). Thus, this shape must have started out growing as a glaze ice accretion and at some point the convective heat transfer value became high enough to switch the growth pattern to that of a rime ice accretion. Just as in the previous business jet airfoil results, this suggests some need to examine the flowfield and resulting convective heat transfer calculations in LEWICE.

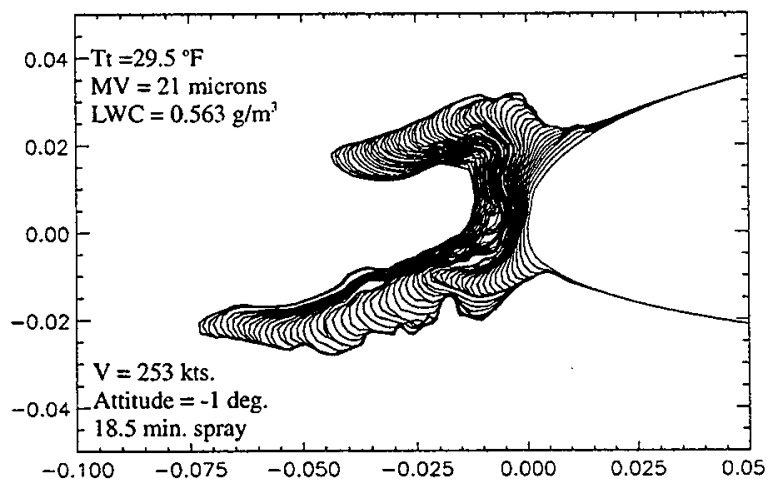

Fig. 24. Ice Growth Pattern Showing LEWICE Calculation Time Steps of Run 123.

The final comparison is for Run \#111, which was a 22.5 minute accretion. Once again, the comparison between LEWICE and experimental results, shown in Figure 25, is good. The code captures the orientation, mass, and icing limits found in the IRT results. The shape of the ice accretions do not agree as well as the other characteristics. The LEWICE shape is not as broad as the IRT

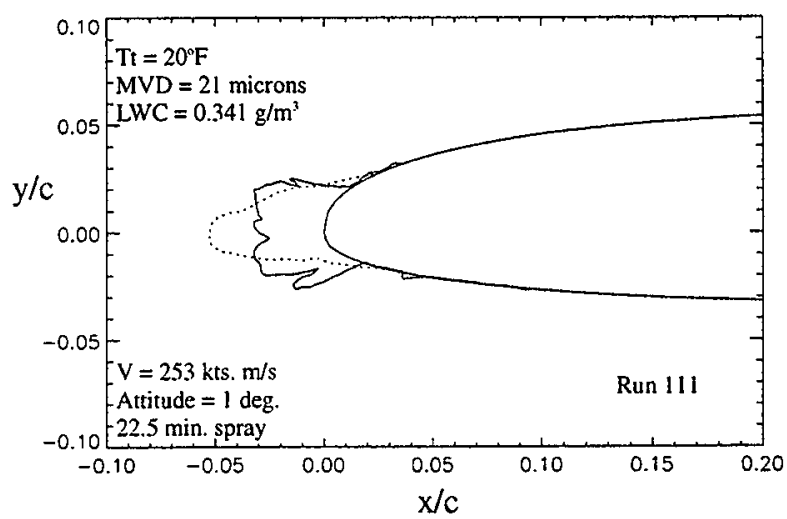

Fig. 25. IRT Ice Shape Comparison with LEWICE Prediction for Commercial Transport Airfoil Section

produced ice shape. The LEWICE results are more indicative of a rime ice accretion while the IRT shape has the flat leading edge indicative of a mixed rime/ glaze accretion.

The results of this comparison of LEWICE generated ice shapes to the experimental measurements from these initial Modern Airfoil entries are encouraging. The LEWICE predictions captured, qualitatively, the nature of the IRT produced ice shapes. There are some apparent differences between computation and experiment. However, these differences seem to be related to aspects of the computational modeling that can be corrected by development of better physical models of the airfoil flow field and the convective heat transfer process occurring during ice accretion. Such efforts are currently underway and although they will not result in a quick fix of the ice accretion model, they do hold out the promise of improved ice accretion predictions in the future.

\section{Conclusions}

\section{Experimental Results}

In the case of the commercial transport airfoil, it was found that exposure to glaze ice conditions for as little as two minutes can have a noticeable effect on lift coefficient, particularly at the higher airfoil angle of attack. The observed angle of stall was also adversely affected by the presence of glaze ice. Rime and mixed ice also reduced lift coefficient and the observed angle of stall for the airfoil, although less significantly than glaze ice.

Similar trends were observed for the business jet airfoil. One difference was that the differing types of ice resulted in about the same decrease in lift coefficient this 
airfoil, whereas the differing ice types resulted in noticably different decreases in lift coefficients for the commercial transport airfoil. For the business jet airfoil, the stall angle was reduced to about the same value for the rime and mixed ice, but was reduced further for the glaze ice.

Results of LEWICE predictions compare reasonably well with the ice shapes formed in the IRT especially in terms of overall shapes and impingement limits. Differences between LEWICE calculation of horn angles and what occurs in the IRT at the same conditions indicates that more investigation of the heat transfer in these regions is warranted. Furthermore, the general underprediction of the amount of ice on the business jet airfoil by LEWICE suggests that thinner airfoils have at least slightly different ice accretion characteristics which LEWICE cannot simulate as well as the thicker airfoils with which the code was primarily developed.

Finally, it should be pointed out that limitations associated with making aerodynamic measurements in an icing wind tunnel suggest that caution should be used when interpreting the results. Cloud nonuniformity, partial span cloud coverage, and potentially complex effects of ice shape on air flow and concomitant tunnel interactions make this a challenging endeavor. Furthermore, two dimensional airfoils can perform quite differently from an actual three dimensional wing in actual flight conditions. In fact, the rather significant reductions in aerodynamic performance caused by the ice shapes in these tests can be designed out of a three dimensional wing or can be well within the margins of safety for the design. Nonetheless, the basic research done here can, if used properly, be used to better understand the ice accretion process on today's aircraft.

\section{$\underline{\text { References }}$}

1. Rae, Jr., W.H., and Pope, A., "Low Speed Wind Tunnel Testing", John Wiley \& Sons, 2nd Ed., 1984, Chap. 6.

2. Anderson, D.N., "Further Evaluation of Traditional Icing Scaling Methods", AIAA 96-0633, NASA TM 107140 , presented at the 34 th Aerospace Sciences Meeting, Reno, NV, Jan. 15-18, 1996.

3. Shin, J. and Bond, T.H., "Repeatability of Ice Shapes in the NASA Lewis Icing Research Tunnel", Journal of Aircraft, Vol. 31, No. 5, Pgs. 1057-1063.

4. Soeder, R.H., Sheldon, D.W., Andracchio, C.R., Ide, R.F., Spera, D.A, and Lalli, N.M.,"NASA Lewis Icing Research Tunnel User Manual", NASA TM 107159, June 1996.
5. Potapczuk, M.G., and Berkowitz, B.M., "Experimental Investigation of Multielement Airfoil Ice Accretion and Resulting Performance Degradation", Journal of Aircraft, Vol. 27, No. 8, Aug. 1990, Pgs. 679-691.

6. Bragg, M.B., Zaguli, R.J., and Gregorek, G.M., "Wind Tunnel Evaluation of Performance Using Simulated Ice Shapes", NASA CR 167960, Nov. 1982.

7. Wright, W.B., "User Manual for the Improved NASA Lewis Ice Accretion Code LEWICE 1.6", NASA CR 198355, June 1995. 
Public reporting burden for this collection of information is estimated to average 1 hour per response, including the time for reviewing instructions, searching existing data sources, gathering and maintaining the data needed, and completing and reviewing the collection of information. Send comments regarding this burden estimate or any other aspect of this collection of information, including suggestions for reducing this burden, to Washington Headquarters Services, Directorate for Information Operations and Reports, 1215 Jefferson Davis Highway, Suite 1204, Artington, VA 22202-4302, and to the Office of Management and Budget, Paperwork Reduction Project (0704-0188), Washington, DC 20503.

\begin{tabular}{|l|l|l|}
\hline 1. AGENCY USE ONLY (Leave blank) & $\begin{array}{r}\text { 2. REPORT DATE } \\
\text { March } 1997\end{array}$ & $\begin{array}{r}\text { 3. REPORT TYPE AND DATES COVERED } \\
\text { Technical Memorandum }\end{array}$ \\
\hline
\end{tabular}

4. TITLE AND SUBTITLE

Modern Airfoil Ice Accretions

6. AUTHOR(S)

Harold E. Addy, Jr., Mark G. Potapczuk, and David W. Sheldon
5. FUNDING NUMBERS

WU-505-68-1C

\section{PERFORMING ORGANIZATION NAME(S) AND ADDRESS(ES)}

National Aeronautics and Space Administration

Lewis Research Center

Cleveland, Ohio 44135-3191
8. PERFORMING ORGANIZATION REPORT NUMBER

E-10667
9. SPONSORING/MONITORING AGENCY NAME(S) AND ADDRESS(ES)

National Aeronautics and Space Administration

Washington, DC 20546-0001
10. SPONSORING/MONITORING AGENCY REPORT NUMBER

NASA TM-107423

AIAA-97-0174

\section{SUPPLEMENTARY NOTES}

Prepared for the 35th Aerospace Sciences Meeting \& Exhibit sponsored by the American Institute of Aeronautics and Astronautics, Reno, Nevada, January 6-10, 1997. Responsible person, Harold E. Addy, Jr., organization code 2720, (216) 977-7467.

12a. DISTRIBUTION/AVAILABILITY STATEMENT

12b. DISTRIBUTION CODE

Unclassified - Unlimited

Subject Category 02

This publication is available from the NASA Center for AeroSpace Information, (301) 621-0390.

13. ABSTRACT (Maximum 200 words)

This report presents results from the first icing tests performed in the Modern Airfoils program. Two airfoils have been subjected to icing tests in the NASA Lewis Icing Research Tunnel (IRT). Both airfoils were two dimensional airfoils; one was representative of a commercial transport airfoil while the other was representative of a business jet airfoil. The icing test conditions were selected from the FAR Appendix C envelopes. Effects on aerodynamic performance are presented including the effects of varying amounts of glaze ice as well as the effects of approximately the same amounts of glaze, mixed, and rime ice. Actual ice shapes obtained in these tests are also presented for these cases. In addition, comparisons are shown between ice shapes from the tests and ice shapes predicted by the computer code, LEWICE for similar conditions. Significant results from the tests are that relatively small amounts of ice can have nearly as much effect on airfoil lift coefficient as much greater amounts of ice and that glaze ice usually has a more detrimental effect than either rime or mixed ice. LEWICE predictions of ice shapes, in general, compared reasonably well with ice shapes obtained in the IRT, although differences in details of the ice shapes were observed.

\section{SUBJECT TERMS}

Modern airfoils; Ice accretions; Business jet main wing; Aerodynamic performance; Large transport horizontal tailplane

\begin{tabular}{|c|c|c|}
\hline $\begin{array}{c}\text { 17. SECURITY CLASSIFICATION } \\
\text { OF REPORT } \\
\text { Unclassified }\end{array}$ & $\begin{array}{c}\text { 18. SECURITY CLASSIFICATION } \\
\text { OF THIS PAGE } \\
\text { Unclassified }\end{array}$ & $\begin{array}{c}\text { 19. SECURITY CLASSIFICATION } \\
\text { OF ABSTRACT } \\
\text { Unclassified }\end{array}$ \\
\hline
\end{tabular}

